\title{
Risk factors for chronic liver disease in population of Central India: a case-control study from rural India
}

\author{
Shashank Banait ${ }^{1}$, Shailesh Mohan Badole ${ }^{2}$, Jyoti Jain ${ }^{3^{*}}$ (ID and Abasaheb Thorat ${ }^{3}$
}

\begin{abstract}
Background: Chronic liver disease (CLD) is one of the leading causes of morbidity and mortality in today's world. Common risk factors for CLD are alcohol, chronic hepatitis B, chronic hepatitis C, non-alcoholic steatohepatitis (NASH), malnutrition, toxins, and some tropical infections. This case-control study was carried out to determine the risk factors of domestic CLD in a resource-constrained setting in central rural India. A hospital-based matched casecontrol study was carried out among eligible CLD cases from November 2015 to October 2017. A total of 200 cases and 200 age- and gender-matched community controls were selected using consecutive sampling from tertiary care hospitals from central rural India. Information on socio-demographic, etiological was collected through using a pretested structured questionnaire after obtaining informed written consent. Univariate and multivariate analyses were carried out to find the risk factors associated with CLD.

Results: The median age of study participant was 58.5 years among the cases. There were $75 \%$ male and remaining $25 \%$ were female in each case and control group. On multivariate analysis, we found less education, poor socioeconomic status, diabetes mellitus, increased body mass index (BMI), alcohol consumption, and tobacco chewing were significant risk factors for CLD in comparison to controls. However, amount of alcohol, smoking, and occupation were not found to be statistically significant association with CLD.

Conclusions: The findings showed that in patients with CLD when compared to controls, high alcohol intake, diabetes mellitus, tobacco chewing, central obesity, low education, and low-income group are significant risk factors in our rural population. An initiative needs to be taken to reduce alcohol, and tobacco chewing habits at various levels through awareness campaigns, strict control, and legislation to limit further abuse. Control of blood glucose and reduction of obesity may be important in preventing CLD in our rural community.
\end{abstract}

Keywords: Alcohol, Chronic liver disease, Cirrhosis of liver, Non-alcoholic steatohepatitis, Risk factors

\section{Background}

Chronic liver disease (CLD) is one of the leading causes of morbidity and mortality in today's world [1]. It is increasingly becoming more prevalent, and part of this rise can be attributed to improved detection and opportunistic screening. Medical researchers are trying continuously to analyze this problem and searching for factors

\footnotetext{
* Correspondence: jyotijain@mgims.ac.in

${ }^{3}$ Department of Medicine, Mahatma Gandhi Institute of Medical Sciences, Sevagram, Wardha, Maharashtra, India

Full list of author information is available at the end of the article
}

that aid in its prevention. Although overall mortality from CLD has shown a gradual decline over the last three to four decades, death rates within certain subgroups have increased over time [2].

The risk factors for CLD may vary in different populations. In developed countries, common risk factors are alcohol, chronic hepatitis B, chronic hepatitis $\mathrm{C}$, and NASH, while in developing countries, predominant causes of cirrhosis are alcoholic, hepatitis $\mathrm{B}$, hepatitis $\mathrm{C}$, malnutrition, toxins, and some tropical infections are common. Moreover, certain risk factors are likely to be region-specific 
such as sickle cell disease in population subgroups where this disease is prevalent. It is important to know risk factors for CLD, so that there is a potential to prevent such exposures. It is also important to know the risk factors in the early stage of CLD, a period which is largely asymptomatic.

Many of the studies had been conducted among western population and very scanty knowledge is available from Indian perspective and especially from rural area. Moreover, it has been observed that many individuals land up in the early stages of CLD with exposure to different risk factors and their progression to the advance stages along with complications of the disease requiring management at high cost and also increased risk of mortality. Thus, the present case-control study was carried out to determine if patients of more than 18 years of age with CLD have a higher exposure of risk factors as compared to age- and gender-matched community controls in a resource-constrained setting in central rural India.

\section{Methods}

This study was conducted in the Department of Medicine at Kasturba Hospital and Mahatma Gandhi Institute of Medical Sciences (MGIMS), Sevagram, India. Kasturba Hospital is a 920-bed rural teaching hospital of central India affiliated to MGIMS. Every year this hospital provides care to about 900,000 outpatients and 50,000 inpatients. We enrolled patients from inpatient settings in this study. Department of Medicine also has an outreach program where trained social workers screen individuals in the community for chronic diseases. Currently, this program runs in a total of 25 villages around our college. This case-control study was conducted from 1 November 2015 to 31 October 2017, after taking approval from the institutional ethics committee of MGIMS (IRB00003623). We obtained a written informed consent from all study participants before enrolling them in the study.

All patients aged 18 years and above admitted to the Medicine wards in Kasturba Hospital, were screened and with incident CLD were identified through a Hospital information system.

The diagnosis of CLD was based on the clinical profile, ultrasonography (USG) abdomen, and biochemical parameters. The cases were defined as those who have one or more of the following evidence suggestive of CLD irrespective of its etiology, i.e., hypoalbuminemia (serum albumin level $<3.5 \mathrm{mg} / \mathrm{dl}$ ) along with any clinical evidence of portal hypertension (variceal bleed, ascites with or without spontaneous bacterial peritonitis, or recovered from hepatic encephalopathy) and/or a diagnostic imaging of abdomen showing raised, altered echotexture suggestive of fatty liver, chronic hepatitis, or cirrhosis or biopsy result consistent with chronic hepatitis or cirrhosis [3].
Criteria for exclusion were non-cirrhotic portal fibrosis, obvious focal liver disease (hydatid cysts, liver abscess, cholangiocarcinoma, hepatocellular carcinoma, and multiple metastasis. Cases not consenting to the study and not a resident of Wardha district were also excluded. We enrolled consecutive inpatients with diagnosis of CLD according to our inclusion and exclusion criteria.

We recruited 200 cases of CLD as per case definition using consecutive sampling from our tertiary care hospital. Apparently, healthy controls with normal serum albumin levels, who are willing for participation in the study, were selected from the outreach service area and were identified only after the case-selection was completed. One healthy community-based control, frequency matched with the case and was within 5 years of age, and of same gender as the case selected. The exclusion criteria for controls were documented history of liver disease in the past (Fig. 1).

\section{Data collection}

Baseline characteristics and clinical data were recorded for all patients. All patients received the standard line of management for CLD. Patients with suspected CLD were undergone hemogram, liver function test (LFT) [alanine transaminase (ALT), aspartate aminotransferase (AST), alkaline phosphatase, serum albumin, and globulin] in the central clinical laboratory. USG of the abdomen to observe liver architecture, liver size, and features of portal hypertension (splenomegaly, ascites, and portal vein diameter) were done by using a Logic GE machine ultrasound system, equipped with a 7.5 Megahertz $(\mathrm{MHz})$ real-time, linear-array transducer B-mode scanner in patients of CLD by an experienced radiologist. Liver echo-texture was recorded as normal or coarse [4].

\section{Measurement of risk factors}

All cases and controls were enquired about the potential risk factors of CLD through a semi-structured pre-coded and pre-tested questionnaire by the research investigator. The interviews were conducted in their local language (Marathi) from all cases and controls in the same manner. The risk factors we enquired into were classified and presented into the following categories: demographic, socioeconomic, anthropometric risk factors, occupational risk factors, past-morbidity related risk factors, and recreational substance use and laboratory measures.

BMI was calculated in all cases and control by the standard method. It was considered as normal from 18.5 to 24.49 , underweight $<18.49$, obese $\geq 25-29.99$, and overweight $\geq 30$ respectively. Blood pressure (BP) was measured in all cases and controls by Omron digital sphygmomanometer. Subjects were assigned as hypertensive if systolic $\mathrm{BP}$ was $\geq 140 \mathrm{mmHg}$ or diastolic BP was $\geq 90 \mathrm{mmHg}$ [5]. 


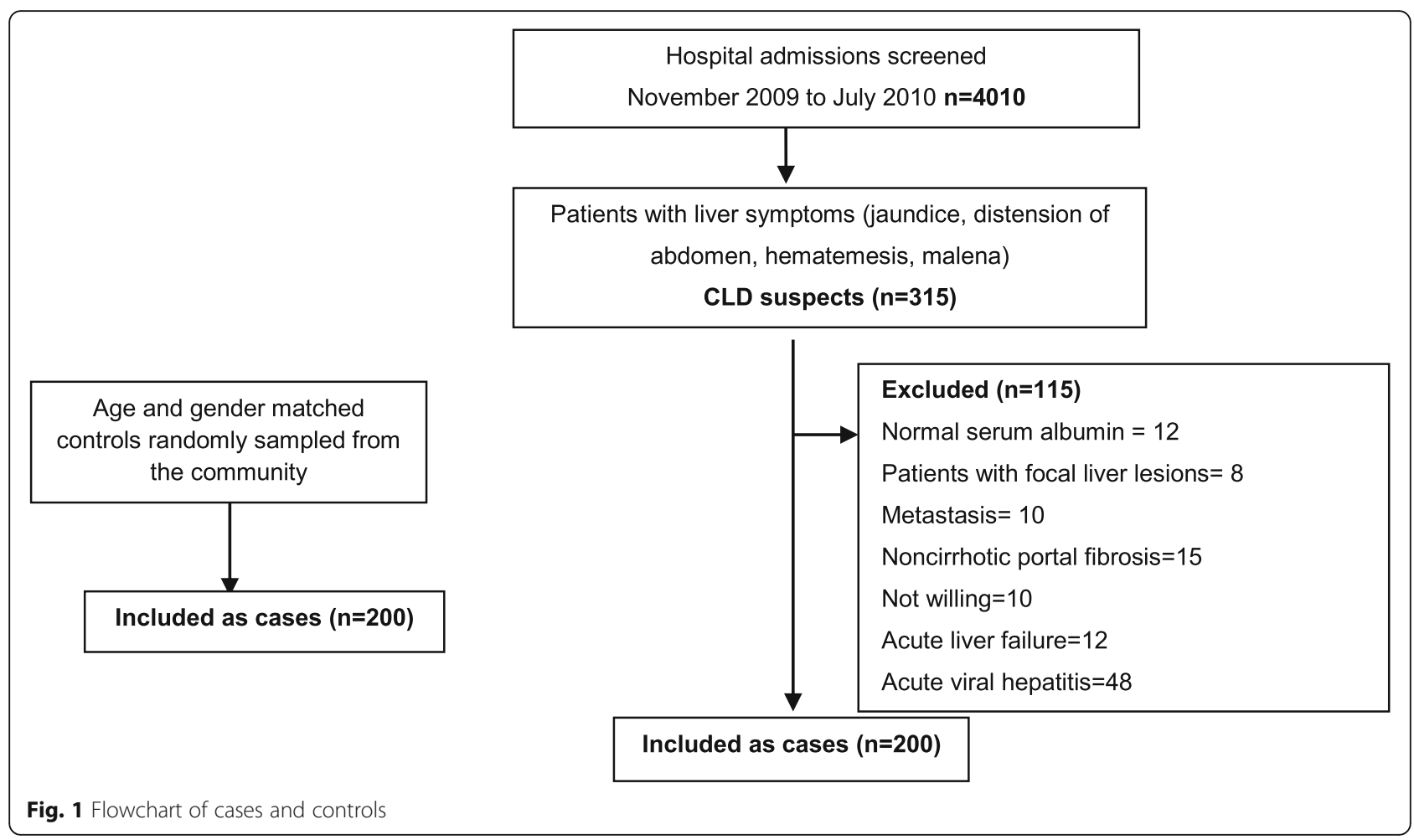

History of occupations like automobile or paint industry (lead, solvents, and engine fumes), mining (silica and sand blasting), construction (cement, asbestos), chemical industry (solvents, chlorine, nitrous gasses), and farming (insecticides, grain dust) were enquired. History of various known and documented diseases was also obtained from all cases and controls: diabetes mellitus, hypertension (HT), or on antihypertensive drugs, history suggestive of rapid weight loss (loss of $>10 \%$ of body weight within 6 months period), intestinal bypass surgery, biliary obstruction in past, polycystic liver disease, sickle cell disease and trait, known HIV infection.

History of chronic recreational substance use [alcohol, smoking tobacco (cigarettes or bidis), tobacco or beetle-nut chewing, intravenous or oral intake of a drug or abuse] with quantification was inquired among cases and controls [6, 7]. We also quantified alcohol intake by asking type of alcohol, frequency, and average amount of alcohol consumption and classified them as never, current, and past (those who had given up drinking for 6 months or more) users. Patients were defined as having non-alcoholic fatty liver disease (NAFLD) if they have a history of consumption of alcohol $\leq 20$ grams/day (g/day) [8-13]. Cases and controls were classified as never smoker (not smoked cigarette or bidi for at least three months in a lifetime), current smoker (smoked at least one cigarette or bidi in the last three months), and former smoker (one who does not meet both criteria).
Chronic consumption (' 3 months) of medications such as corticosteroids, methotrexate, amiodarone, methyldopa or herbal or folk remedies, or alternative medicine was also asked from all study participants.

In addition, venous blood samples after a 12-h overnight fast from all enrolled patients were collected for estimation of biochemical test. The collected sera were immediately refrigerated till they were tested by a serologist who was unaware of the clinical data of the patients. Hepatitis B surface antigen ( $\mathrm{HbsAg}$ ) and anti-hepatitis $\mathrm{C}$ antibodies qualitative detection ( $\mathrm{HCV}$ ) was done by rapid immunochromatographic assay. Venous blood samples transported within $6 \mathrm{~h}$ to central laboratory of hospital for lipid panel [total cholesterol, high-density lipoprotein cholesterol (HDL-C), low-density lipoprotein cholesterol (LDLC), triglycerides (TG)] measurement by standard enzymatic tests. Levels were considered abnormal if total cholesterol $>200 \mathrm{mg} / \mathrm{dl}$, LDL-C $>130 \mathrm{mg} / \mathrm{dl}$, TG $>150 \mathrm{mg} / \mathrm{dl}$, and HDL-C $<40 \mathrm{mg} / \mathrm{dl}$ respectively. Random glucose and serum creatinine were also obtained on day 1 in all enrolled participants.

\section{Data management and analysis}

We entered the data electronically by Microsoft Excel and analyzed by STATA software (Version 16, Stata Corporation, TX, USA). We analyzed normally distributed continuous variables by Student's $t$ test, proportions by a chi-square test and continuous variables with skewed distribution by a Mann-Whitney test. We 
considered a $p$ value of less than 0.05 as significant. Exposure-related variables were included in the logistic regression analysis used in the multivariate model if they displayed a $p$ value $<0.02$ in the bivariate analysis. We calculated the odds ratios (ORs) as a measure of risk and 95\% confidence interval (CI) associated with the independent variables.

\section{Results}

During the study, we screened 4010 consecutive patients with symptoms of liver disease and found 315 clinically suspected CLD. Finally, 200 patients who had fulfilled one or more of the inclusion criteria suggestive of CLD were included to the study, and 115 patients were excluded (Fig. 1).

The demographic and socioeconomic profile of the study population is shown in Table 1. Matching could achieve similar age and gender distribution among cases and controls. Among 200 cases and 200 controls, 150 (75\%) were males; with median age $58.5 \pm 11.8$ and $57 \pm$ 11.7 among cases and controls respectively. Majority of the study participants were in the age group of 41-65 years contributing $72.5 \%$ among cases and $70 \%$ among controls. Socioeconomic indicators and educational status were different statistically significant in patients with CLD when compared to controls with $p$ value of 0.00001 and 0.000004 respectively. Among cases and controls commonest occupation was farming (60.8\%); BMI was in normal range in $62.5 \%$ cases and $45.5 \%$ controls. Among the cases, $13(6.5 \%)$ and $3(1.5 \%)$ were found to have $\mathrm{HbsAg}$ and $\mathrm{HCV}$ positive respectively while none of the controls were positive for $\mathrm{HbsAg}$ and $\mathrm{HCV}$. There were total of 62 patients with history suggestive of alcohol intake $<20 \mathrm{~g} / \mathrm{dl}$ and 52 out of them fulfilled the criteria NAFLD. Symptoms among patients of CLD are depicted in Fig. 2.

On univariate analysis, odds of being farmers, shopkeepers, and students were found to have significant association with CLD ( $p=0.00001,0.00002$, and 0.03) respectively. Cases with exposure to insecticide and grain dust were found to have significant association with $p$ value of 0.00001 each when compared to controls while asbestos exposure did not show significant association with CLD. In comparison of past-morbidity related risk factors among cases and controls, diabetes was found to have a significant association with CLD with $p$ value of 0.0008 ; while past history of $\mathrm{HT}$, pulmonary tuberculosis, ischemic heart disease, sickle cell disease, chronic obstructive airway disease, and human immunodeficiency virus were not found to have significant association with CLD. None of the cases and controls had past history of intestinal bypass surgery, biliary obstruction, and polycystic liver disease. BMI of underweight, normal, and overweight participants were found to have significant association $(p=0.000001,0.00065$, and 0.000027) respectively with CLD (Table 2).

Table 1 Distribution of demographic and socio-economic variables among cases and controls $(n=400)$

\begin{tabular}{|c|c|c|c|}
\hline Variable & Cases $200(\%)$ & Controls 200 (\%) & $P$ value \\
\hline \multicolumn{4}{|l|}{ Age } \\
\hline $18-40$ years & $26(18 \%)$ & $24(12 \%)$ & $>0.05$ \\
\hline $41-65$ years & $143(72.5 \%)$ & $140(70 \%)$ & 0.96 \\
\hline 66 years or more & $31(15.5 \%)$ & $36(18 \%)$ & \\
\hline Median age (in years) & $58.5 \pm 11.8$ & $57 \pm 11.7$ & 0.95 \\
\hline \multicolumn{4}{|l|}{ Gender } \\
\hline Male & $150(75 \%)$ & $150(75 \%)$ & \\
\hline Female & $50(25 \%)$ & $50(25 \%)$ & 1 \\
\hline \multicolumn{4}{|c|}{ Number of material possessions } \\
\hline One to two & $0(0 \%)$ & $49(12.3)$ & 0.00001 \\
\hline Three to four & $19(4.8 \%)$ & $104(26 \%)$ & \\
\hline Five to eight & $111(27.7 \%)$ & $47(11.8 \%)$ & \\
\hline More than nine & $70(17.4 \%)$ & $0(6.8 \%)$ & \\
\hline \multicolumn{4}{|l|}{ Education } \\
\hline Less than middle school & $128(64 \%)$ & $187(93.5 \%)$ & 0.0003 \\
\hline More than middle school & $72(36 \%)$ & $13(6.5 \%)$ & \\
\hline \multicolumn{4}{|l|}{ Residence } \\
\hline Rural & $156(78 \%)$ & $200(100 \%)$ & 0.000004 \\
\hline Urban & $44(22 \%)$ & $00(0.00 \%)$ & \\
\hline
\end{tabular}




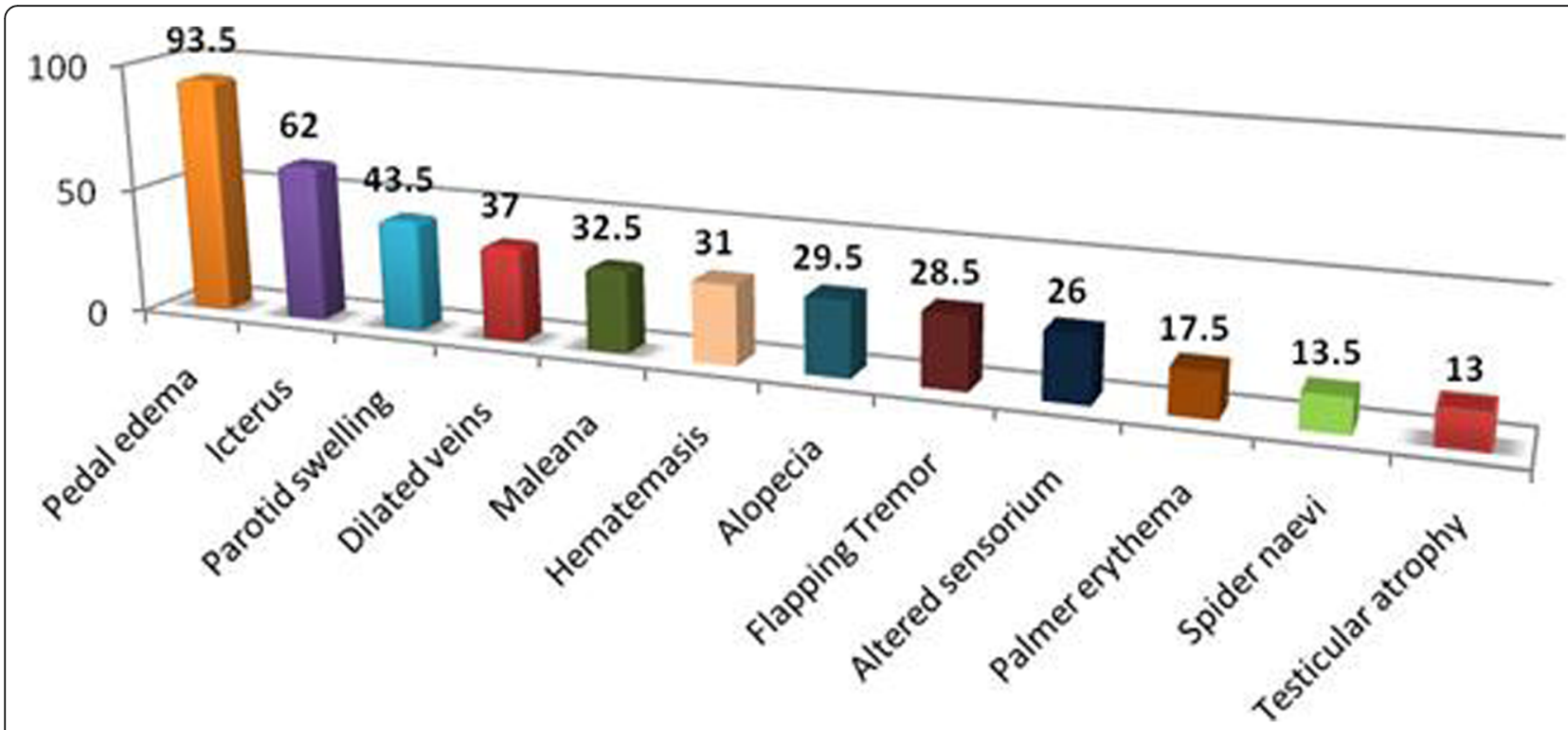

Fig. 2 Symptoms and signs among the cases of chronic liver disease

On recreational substance abuse history ever use of alcohol, smoking, and tobacco were found to have statistically significant association with CLD with $p$ value of (0.0000001, 0.0001, and 0.000027) respectively. Alcohol consumption rate in g/day when compared between groups of 0 to $19 \mathrm{~g} / \mathrm{dl}$ vs > $20 \mathrm{~g} /$ day also showed significant $(p=0.00001)$ association with CLD. Hepatitis B was found to have a significant association with CLD $(p=0.00025)$. On analysis of lipid profile, there was a significant association between having low total cholesterol and LDL with CLD, but with hypertriglyceridemia and low HDL, there was no increased risk of CLD was found.

Final model derived by multivariate logistic regression suggested that the significant risk factors for CLD were less education, poor socioeconomic status, diabetes mellitus, increased BMI, alcohol consumption, and tobacco chewing. Significant risk factors for CLD derived by univariate and multivariate logistic regression by final model are shown in Table 3.

\section{Discussion}

Our case-control study showed that less education, poor socioeconomic status, diabetes mellitus, increased BMI, alcohol consumption, and tobacco chewing were risk significant factors for CLD in comparison to controls. Some factors such as occupation, smoking, and hepatitis $B$ were significant on univariate analysis, but when adjusted for other risk factors were not found to be significant. Other known risk factors such as hepatitis C, hyperlipidemia, and HT were not found to be significant in our age and gender-matched case-control study.

The median age of study participants in our study was 58.5 years among cases and 57 years in controls were similar to various studies done on CLD patients; however, male-female ratio was not similar as more males were found to have CLD in our study [14-16]. These differences might be due to predominance of alcohol intake and health-seeking behavior among males in our community. Most of the study participants had education less than middle school which was $64 \%$ and $93.5 \%$ among cases and controls respectively, which was more than the study done by Frieden et al., 52\% cases and 54\% controls with education less than middle school [17]. This difference of education might be because of the selection of $78 \%$ cases and all controls from rural area with poor socioeconomic status and underprivileged resources for higher education.

Farmers, shopkeepers, and students were found to have significant association with CLD while Zhang et al. reported farmers, laborers, and small businessmen as risk factors for CLD [18].

The results of our study showed diabetes as a significant risk factor for CLD with $10 \%$ and $1 \%$ among cases and controls respectively while in retrospective study, diabetes was found in 23\%, which was more than our study [14].

Among recreational substance abuse ever use of alcohol, smoking and tobacco were found to have statistically significant association with CLD. Similar results were found by Lin et al. in their study [19]; however, Steffensen et al. found statistically significant association of smoking only with CLD [20]. Our study showed that the amount of alcohol consumed and CLD are closely associated and results of our study were similar to the various studies [21, 22]. Coates et al. also concluded that as the amount of alcohol per day increases, the risk of 
Table 2 Univariate analysis of risk factors for chronic liver disease

\begin{tabular}{|c|c|c|c|c|c|}
\hline & Cases $(n=200)$ & Controls $(n=200)$ & Odds ratio $(95 \% \mathrm{Cl})$ & Chi-square & $P$ value \\
\hline \multicolumn{6}{|l|}{ Occupation } \\
\hline Farmer & $100(50 \%)$ & $143(71.5 \%)$ & $0.40(0.26-0.62)$ & 19.34 & 0.00001 \\
\hline Laborer & $14(7 \%)$ & $20(10 \%)$ & $0.68(0.31-1.46)$ & 1.16 & 0.28 \\
\hline Service & $16(8 \%)$ & $13(6.5 \%)$ & $1.25(0.55-2.85)$ & 0.33 & 0.56 \\
\hline Student & $6(3 \%)$ & $0(0 \%)$ & & 6.08 & 0.03 \\
\hline Housewife & $19(9.5 \%)$ & $13(6.5 \%)$ & $1.51(0.69-3.35)$ & 1.22 & 0.26 \\
\hline Shopkeeper & $45(22.5 \%)$ & $11(5.5 \%)$ & $4.99(2.39-10.61)$ & 24 & 0.00002 \\
\hline \multicolumn{6}{|l|}{ Alcohol consumption (g/day) } \\
\hline $0-19$ & $62(24.7 \%)$ & $189(75.3 \%)$ & & & \\
\hline $20-59$ & $31(77.5 \%)$ & $9(22.5 \%)$ & $10.50(4.48-25.25)$ & 44.08 & 0.00001 \\
\hline $60-79$ & 78 (97.5\%) & $2(2.5 \%)$ & $118.89(27.58-720)$ & 131.3 & 0.00001 \\
\hline$>80$ & $29(100 \%)$ & $0(0.0 \%)$ & & 67.95 & 0.00001 \\
\hline \multicolumn{6}{|l|}{ Past diseases } \\
\hline Hypertension & $26(13 \%)$ & $26(13 \%)$ & $1(0.54-1.86)$ & 0 & 1 \\
\hline Diabetes & $20(10 \%)$ & $2(1 \%)$ & $11(2.44-69.09)$ & 15.55 & 0.00008 \\
\hline Pulmonary TB & $3(1.5 \%)$ & $0(0 \%)$ & & 3.02 & 0.24 \\
\hline $\mathrm{HD}$ & $5(2.5 \%)$ & $0(0 \%)$ & & 5.05 & 0.061 \\
\hline COPD & $1(0.5 \%)$ & $0(0 \%)$ & & 1 & 1 \\
\hline HIV & $1(0.5 \%)$ & $0(0 \%)$ & & 1 & 1 \\
\hline Sickle cell disease and trait & $2(1 \%)$ & $0(0 \%)$ & & 2.01 & 0.49 \\
\hline \multicolumn{6}{|l|}{ BMI (kg/m2) } \\
\hline Underweight (0-18.49) & $24(12 \%)$ & 87 43.5\%) & $0.18(0.1-0.3)$ & 49.37 & 0.000001 \\
\hline Normal (18.5-24.99) & $125(62.5 \%)$ & 91 (45.5\%) & $2(1.3-3)$ & 11.61 & 0.00065 \\
\hline Overweight (25-29.99) & $48(24 \%)$ & $17(8.5 \%)$ & $3.40(1.1-6.4)$ & 17.61 & 0.000027 \\
\hline Obese (> 30) & $3(1.5 \%)$ & $5(2.5 \%)$ & $0.59(0.1-2.9)$ & 0.51 & 0.7237 \\
\hline \multicolumn{6}{|l|}{ Viral markers } \\
\hline $\mathrm{HbsAg}$ & $13(6.5 \%)$ & $0(0 \%)$ & & 13.44 & 0.00025 \\
\hline $\mathrm{HCV}$ & $03(1.5 \%)$ & $0(0 \%)$ & & 3.02 & 0.12 \\
\hline \multicolumn{6}{|l|}{ Lipid profile (mg/dl) } \\
\hline $\mathrm{TCL}$ & & & $0.09(0.02-0.32)$ & 22.9 & 0.000001 \\
\hline$>200$ & 3 & 29 & & & \\
\hline$<200$ & 197 & 171 & & & \\
\hline HDL & & & $1.87(0.87-4.04)$ & 3.04 & 0.0809 \\
\hline$<35$ & 23 & 13 & & & \\
\hline$>35$ & 177 & 187 & & & \\
\hline LDL & & & $0.26(0.09-0.71)$ & 8.91 & 0.0028 \\
\hline$>130$ & 6 & 21 & & & \\
\hline$<130$ & 194 & 179 & & & \\
\hline TG & & & $1.34(0.09-2.61)$ & 0.88 & 0.3476 \\
\hline$>150$ & 26 & 20 & & & \\
\hline$<150$ & 174 & 180 & & & \\
\hline
\end{tabular}


Table 3 Multivariate conditional logistic regression of risk factors for chronic liver disease

\begin{tabular}{|c|c|c|c|c|c|c|}
\hline & Odds ratio & 95\% C.I. & Coefficient & S. E. & $Z$ statistic & $P$ value \\
\hline Alcohol consumption rate (g/day) & 27.41 & $5.6-133.16$ & 3.3109 & 0.8065 & 4.1054 & 0.0001 \\
\hline BMI (kg/m2) & 3.61 & $1.5-8.71$ & 1.2848 & 0.4489 & 2.8623 & 0.0042 \\
\hline Diabetes mellitus (RBS $<200$ or $>200$ mg/dl) & 24.11 & $1.2-472.48$ & 3.1827 & 1.5181 & 2.0965 & 0.0360 \\
\hline Education (< middle school or $>$ middle school) & 12.35 & $2.4-63.31$ & 2.5140 & 0.8338 & 3.0152 & 0.0026 \\
\hline Smoking (ever use) & 0.43 & $0.09-2.084$ & -0.8372 & 0.8020 & -1.0439 & 0.2965 \\
\hline Tobacco (ever use) & 7.48 & $1.46-38.4075$ & 2.0127 & 0.8345 & 2.4120 & 0.0159 \\
\hline Material possession & 0.11 & $0.01-0.8209$ & 2.2363 & 1.0403 & 2.1497 & 0.0316 \\
\hline Occupation & 0.96 & $0.63-1.4695$ & 0.0401 & 0.2168 & 0.1850 & 0.8532 \\
\hline
\end{tabular}

Final-2*Log-Likelihood: 46.9463

development of cirrhosis increases (at 40 to $59 \mathrm{~g} /$ dayrelative risk 1.37 , at 60 to $79 \mathrm{~g} /$ day-relative risk 4 , at > $80 \mathrm{~g} /$ day it was 50) [23].

In our study on univariate analysis, hepatitis B was found statistically significant ( $p$ value 0.00025$)$ with CLD, while hepatitis $C$ was not found to be statistically significant. In our study, the commonest probable reason for development of CLD was alcohol in 69\% of the participants, while NAFLD and hepatitis B were found in $26 \%$ and $7.5 \%$ respectively. Alcohol had been reported as the most common probable reason for development of CLD by various studies conducted in past $[14,15]$. However, Frieden et al. reported combination of alcohol and hepatitis $\mathrm{C}$ as the commonest probable reason for development of CLD followed by alcohol alone [17] (Table 4). Another study reported NAFLD as the commonest probable reason for development of CLD followed by combination of alcohol and hepatitis B [28]. These differences in our study with respect to other studies might be due to consumption of large amount, locally made alcohol and nutritional deficient diet along with low prevalent incidence of hepatitis $B$ and $C$ in our study suggests that these sexually transmitted and blood-borne disease were less among the cases either due to safe sex practices or practice of universal safety precautions. Significant relationship between lipid level and development of NAFLD is found in various studies, but our study did not revealed statistical significance between lipid levels and NAFLD [18, 24-26, 29].

In our study, BMI of participants was found to have significant association with CLD, however, there was no significant association of BMI among NAFLD and non-NAFLD group. In a few studies, BMI $>25$ was found to be significant in the NAFLD group [18, 27] (Table 4). These differences may be due to involvement of rural population among our study with poor socioeconomic status.

On multivariate analysis, our study showed that less education, poor socioeconomic status, diabetes mellitus, increased BMI, alcohol consumption, and tobacco chewing were significant risk factors for CLD in comparison to controls.
This case-control study for risk factors of CLD is one of the few from rural India, which has a different risk factor profile as compared to urban areas, as well as from other developed countries. We used standard definitions for classification of CLD and we performed an extensive literature search and have presented an updated review of CLD risk factor literature. The sample size of the study population (200 cases and 200 controls) was adequate. Another strength of our study was that we have taken controls from the community rather than from the hospital. Our study has certain limitations also. First, is selection bias. Although the control sampling was from community, numerically a higher proportion of controls per case would have improved the risk factor profile among controls. Second, is information bias. History aims to capture presence of risk factors prior to onset of CLD. When the onset of disease is uncertain, it remains difficult to ascertain if risk factors were really present prior to onset of disease. Further, information bias could also result due to interviewer bias, as the interviewer is unblinded to the case and control status of individuals. Third, casecontrol study design has some inherent limitations, such as inability to prove a temporal association between presence of a risk factor and outcome. Further control selection depends on some assumptions such as the prevalence of risk factors in controls representing the community as a whole, which might not have been adequately addressed in the study design. Lastly, we did not study risk factors such as history of blood transfusion and unsafe sex in our study. Our patients being from rural background do not disclose their sex-related issues clearly, so we thought not to include this variable as a risk factor; however, we have tested all the study participants for hepatitis B and hepatitis $\mathrm{C}$.

Despite these limitations, the current study clearly delineates what may be the priorities in terms of risk reduction for CLD as alcohol, hepatitis, and NAFLD are clear-cut risk factors which may be associated with development for CLD. 
Table 4 Comparison of various studies with present study on risk factors of chronic liver disease

\begin{tabular}{|c|c|c|c|c|c|c|c|c|c|c|}
\hline & $\begin{array}{l}\text { Kudava } \\
\text { et al. [15] }\end{array}$ & $\begin{array}{l}\text { Mishra et al. } \\
\text { [16] }\end{array}$ & $\begin{array}{l}\text { Frieden } \\
\text { et al. [18] }\end{array}$ & $\begin{array}{l}\text { Chen } \\
\text { et al. } \\
{[24]}\end{array}$ & $\begin{array}{l}\text { Singh et al. } \\
{[25]}\end{array}$ & $\begin{array}{l}\text { Tellez-Avila } \\
\text { et al. [26] }\end{array}$ & $\begin{array}{l}\text { Stepanova } \\
\text { et al. [27] }\end{array}$ & $\begin{array}{l}\text { Zhang } \\
\text { et al. [19] }\end{array}$ & $\begin{array}{l}\text { Madan } \\
\text { et al. } \\
\text { [29] }\end{array}$ & Our study \\
\hline $\begin{array}{l}\text { Type of the } \\
\text { study }\end{array}$ & Retrospective & Retrospective & $\begin{array}{l}\text { Case } \\
\text { control }\end{array}$ & $\begin{array}{l}\text { Cross- } \\
\text { sectional }\end{array}$ & Retrospective & Retrospective & Retrospective & Prospective & $\begin{array}{l}\text { Cross- } \\
\text { sectional }\end{array}$ & $\begin{array}{l}\text { Case } \\
\text { control }\end{array}$ \\
\hline Year & 1990 & 2009 & 1999 & 2006 & 2010 & 2008 & 2010 & 2011 & 2006 & 2009-2010 \\
\hline $\begin{array}{l}\text { No. of } \\
\text { participants }\end{array}$ & 80 & 74 & $\begin{array}{l}52 \text { cases, } \\
104 \\
\text { controls }\end{array}$ & 371 & 60 & 134 & 964 & 4072 & 51 & $\begin{array}{l}200 \text { cases, } \\
200 \\
\text { controls }\end{array}$ \\
\hline Age (years) & & & & & $35.1 \pm 8$ & 57 & $47 \pm 11.2$ & $49 \pm 11.1$ & 34 & $51.1 \pm 12.1$ \\
\hline $\begin{array}{l}\text { Male: Female } \\
\text { ratio }\end{array}$ & & & & & $4: 1$ & $1: 1.6$ & $1: 1.6$ & $1: 1.8$ & $9.2: 1$ & $1: 4.2$ \\
\hline BMl & & & & & $25.2 \pm 3.6$ & $27 \pm 4.6$ & $36.1 \pm 9.1$ & $27.2 \pm 5.3$ & 26.7 & $22.7 \pm 4.2$ \\
\hline $\begin{array}{l}\mathrm{BMl}>30 \mathrm{~kg} / \\
\mathrm{m}^{2}\end{array}$ & & & & & NA & $16.8 \%$ & NA & $19.6 \%$ & NA & $1.9 \%$ \\
\hline DM & & & & & $8.33 \%$ & $40 \%$ & $28.1 \%$ & $10 \%$ & NA & $21.1 \%$ \\
\hline Hypertension & & & & & NA & $29.1 \%$ & $44 \%$ & NA & NA & $25 \%$ \\
\hline Alcohol & $36 \%$ & $60.8 \%$ & $29 \%$ & $0.8 \%$ & & & & & & $69 \%$ \\
\hline $\begin{array}{l}\text { Alcohol + } \\
\text { Hepatitis B }\end{array}$ & NA & NA & $6 \%$ & $28.5 \%$ & & & & & & $3 \%$ \\
\hline $\begin{array}{l}\text { Alcohol + } \\
\text { Hepatitis C }\end{array}$ & NA & NA & $46 \%$ & $13.2 \%$ & & & & & & $1 \%$ \\
\hline Hepatitis C & NA & $6.7 \%$ & $6 \%$ & NA & & & & & & $0.5 \%$ \\
\hline Hepatitis B & $33 \%$ & 8.1 & NA & NA & & & & & & $3.5 \%$ \\
\hline NAFLD & $34 \%$ & $13.5 \%$ & NA & $33.6 \%$ & & & & & & $26 \%$ \\
\hline RBS & & & & & NA & NA & $108 \pm 29$ & NA & 90 & $124 \pm 56.1$ \\
\hline ALT (IU/L) & & & & & $\begin{array}{l}110.82 \pm \\
40.99\end{array}$ & $52.5 \pm 39$ & $58.5 \pm 52.8$ & NA & 98 & $\begin{array}{l}54.31 \pm \\
31.7\end{array}$ \\
\hline AST (IU/L) & & & & & $70.6 \pm 23.67$ & $67.1 \pm 60$ & $42.4 \pm 33.9$ & NA & 66 & $\begin{array}{l}95.46 \pm \\
43.0\end{array}$ \\
\hline AST:ALT ratio & & & & & $0.7 \pm 0.3$ & NA & NA & NA & NA & $2.2 \pm 1.1$ \\
\hline $\begin{array}{l}\text { Triglycerides } \\
(\mathrm{mg} / \mathrm{dl})\end{array}$ & & & & & NA & $92.4 \pm 49$ & $167 \pm 107$ & NA & 145 & $87.5 \pm 38.8$ \\
\hline $\begin{array}{l}\text { Total } \\
\text { cholesterol } \\
(\mathrm{mg} / \mathrm{dl})\end{array}$ & & & & & NA & NA & $191 \pm 45$ & NA & 180 & $\begin{array}{l}131.7 \pm \\
39.1\end{array}$ \\
\hline LDL (mg/dl) & & & & & NA & NA & $108.6 \pm 40$ & NA & NA & $56.8 \pm 32.2$ \\
\hline $\mathrm{HDL}(\mathrm{mg} / \mathrm{dl})$ & & & & & NA & $43.4 \pm 10.9$ & $47.1 \pm 13.8$ & NA & 41 & $45.9 \pm 16.6$ \\
\hline
\end{tabular}

\section{Conclusion}

- In patients with CLD when compared to controls high alcohol intake, diabetes mellitus, tobacco chewing, central obesity, low education, and lowincome group are significant risk factors in our rural population.

- An initiative needs to be taken to reduce alcohol consumption and tobacco chewing habits at various levels through awareness campaigns, strict control, and legislation to limit further abuse.
- Control of blood glucose and reduction of obesity probably by increased physical activity and dietary modifications may be important in preventing CLD in our rural community.

\section{Abbreviations}

ALT: Alanine transaminase; AST: Aspartate aminotransferase; BMI: Body mass index; BP: Blood pressure; CLD: Chronic liver disease; Cl: Confidence interval; g/day: Grams/day; HbsAg: Hepatitis B surface antigen; HCV: Anti-hepatitis C antibodies; HDL-C: High-density lipoprotein cholesterol; HT: Hypertension; LFT: Liver function test; LDL-C: Low-density lipoprotein cholesterol; MHz: Megahertz; MGIMS: Mahatma Gandhi Institute of Medical Sciences; NAFLD: Non-alcoholic fatty liver disease; NASH: Non-alcoholic steatohepatitis; ORs: Odds ratios; TG: Triglycerides; USG: Ultrasonography 


\section{Acknowledgements}

Not applicable.

\section{Authors' contributions}

SB contributed to the design and implementation of the research, contributed to the revision of the work, and the acceptance of the final form of the manuscript. 2-SMB contributed to the design and implementation of the research, aided in choosing the patients and helped shape the research, supervised the findings of this work, and discussed the results. 3-J formulated the research idea, contributed to the design and implementation of the research, contributed in the collection of the data, and in performing the statistical part of the work. 4-AST contributed to the design and implementation of the research and performed the laboratory work. All authors provided critical feedback and helped shape the research, analysis, and manuscript. All authors have read and approved the final manuscript.

\section{Funding}

Not applicable.

\section{Availability of data and materials}

All data used and/or analyzed during the current study are available from the corresponding author on reasonable request.

\section{Ethics approval and consent to participate}

All subjects involved in the study signed an informed written consent to participate. This study was performed in accordance with the standards of the ethical research committee of MGIMS, Sevagram (reference number: IRB00003623).

\section{Consent for publication}

Not applicable.

\section{Competing interests}

The authors declare that they have no competing interests.

\section{Author details}

'Department of Ophthalmology, JNMC Sawangi, Wardha, Maharashtra, India. 2DNB Neurology, Russh Super Speciality Hospital, Hyderabad, Telangana, India. ${ }^{3}$ Department of Medicine, Mahatma Gandhi Institute of Medical Sciences, Sevagram, Wardha, Maharashtra, India.

Received: 14 October 2020 Accepted: 7 January 2021

Published online: 27 January 2021

\section{References}

1. Heron M, Hoyert DL, Murphy SL, Xu J, Kochanek KD, Tejada-Vera B (2009) Deaths: final data for 2006. Natl Vital Stat Rep 57:1-134

2. Vong S, Bell BP (2004) Chronic liver disease mortality in the United States, 1990-1998. Hepatology 39:476-483

3. Harriman S.A (1999) New country liver study. State of Connecticut, Department of Public Health 2-7

4. Bruneton JN. Diagnostic ultrasound, Carol M. Rumack, Stephanie R. Wilson, JW Charbonneau, J-. AM Johnson (Eds.), Elsevier/Mosby, Philadelphia, PA (2005), Volume 1: chapter 4,pages 77

5. Chobanian AV, Bakris GL, Black HR, Cushman WC, Green LA, Izzo JL Jr, Jones DW, Materson BJ, Oparil S, Wright JT Jr, Roccella EJ (2003) Seventh report of the Joint National Committee on Prevention, Detection, Evaluation, and Treatment of High Blood Pressure. Hypertension 42:1206-1252

6. Reynolds K, Lewis B, Nolen JD, Kinney GL, Sathya B, He, J. (2003) Alcohol consumption and risk of stroke: a meta-analysis. JAMA 289:579-588

7. DR ALA ALWAN, ASSISTANT DIRECTOR-GENERAL, NONCOMMUNICABLE DISEASES AND MENTAL HEALTH \& WORLD HEALTH ORGANIZATION 2011. Global status report on alcohol and health, WHO Report 2011. In: NONCOMMUNICABLE DISEASES AND MENTAL HEALTH \& ORGANIZATION, W. H. (eds.)

8. Adams LA, Angulo P, Lindor KD (2005) Nonalcoholic fatty liver disease. CMAJ 172:899-905

9. Sanyal AJ, Campbell-Sargent C, Mirshahi F, Rizzo WB, Contos MJ, Sterling RK Luketic VA, Shiffman ML, Clore JN (2001) Nonalcoholic steatohepatitis: association of insulin resistance and mitochondrial abnormalities. Gastroenterology 120:1183-1192
10. CHOI SS, DIEHL AM (2008) Hepatic triglyceride synthesis and nonalcoholic fatty liver disease. Curr Opin Lipidol 19:295-300

11. Mccullough AJ (2002) Update on nonalcoholic fatty liver disease. J Clin Gastroenterol 34:255-262

12. Das K, Kar P (2005) Non-alcoholic steatohepatitis. J Assoc Physicians India 53:195-199

13. Wanless IR, Lentz JS (1990) Fatty liver hepatitis (steatohepatitis) and obesity: an autopsy study with analysis of risk factors. Hepatology 12:1106-1110

14. Kudva MV, Zawawi MM (1990) Chronic liver disease in Kuala Lumpur, Malaysia: a clinical study. Singapore Med J 31:368-373

15. Mishra AK, SP, Bista NR, Bhurtel P, Bhattarai S, Thakali K, Banthia P, Pathak SR (2009) Pattern of liver diseases. J Nepal Health Res Council 7:14-18

16. Corrao G, Arico S (1998) Independent and combined action of hepatitis C virus infection and alcohol consumption on the risk of symptomatic liver cirrhosis. Hepatology 27:914-919

17. Frieden TR, Ozick L, Mccord C, Nainan OV, Workman S, Comer G, Lee TP, Byun KS, Patel D, Henning KJ (1999) Chronic liver disease in central Harlem: the role of alcohol and viral hepatitis. Hepatology 29:883-888

18. Zhang $H$, Jiang YF, He SM, Sun J, Gu Q, Feng XW, Du B, Wang W, Shi XD, Wang CY, Zhang SQ, Li WY, Niu JQ (2011) Etiology and prevalence of abnormal serum alanine aminotransferase levels in a general population in Northeast China. Chin Med J (Engl) 124:2661-2668

19. Lin HH, Wang LY, Shaw CK, Cheng ML, Chung WK, Chiang HJ, Lin TY, Chen CJ (2002) Combined effects of chronic hepatitis virus infections and substance-use habits on chronic liver diseases in Taiwanese aborigines. Formos Med Assoc 101:826-834

20. Steffensen FH, Sorensen HT, Brock A, Vilstrup H, Lauritzen T (1997) Alcohol consumption and serum liver-derived enzymes in a Danish population aged 30-50 years. Int J Epidemiol 26:92-99

21. Tuyns AJ, Pequignot G (1984) Greater risk of ascitic cirrhosis in females in relation to alcohol consumption. Int J Epidemiol 13:53-57

22. Lau K, Freyer-Adam J, Coder B, RIEDEL J, Rumpf HJ, John U, Hapke U (2008) Dose-response relation between volume of drinking and alcohol-related diseases in male general hospital inpatients. Alcohol Alcohol 43:34-38

23. Coates RA, Halliday ML, Rankin JG, Feinman SV, Fisher MM (1986) Risk of fatty infiltration or cirrhosis of the liver in relation to ethanol consumption: a case-control study. Clin Invest Med 9:26-32

24. Tellez-Avila FI, Sanchez-Avila F, Garcia-Saenz-de-Sicilia M, Chavez-Tapia NC, Franco-Guzman AM, Lopez-Arce G, Cerda-Contreras E, Uribe M (2008) Prevalence of metabolic syndrome, obesity and diabetes type 2 in cryptogenic cirrhosis. World J Gastroenterol 14:4771-4775

25. Stepanova M, Aquino R, Alsheddi A, Gupta R, Fang Y, Younossi Z (2010) Clinical predictors of fibrosis in patients with chronic liver disease. Aliment Pharmacol Ther 31:1085-1094

26. Singh DK, Rastogi A, Sakhuja P, Gondal R, Sarin SK (2010) Comparison of clinical, biochemical and histological features of alcoholic steatohepatitis and non-alcoholic steatohepatitis in Asian Indian patients. Indian J Pathol Microbiol 53:408-413

27. Marchesini G, Bugianesi E, Forlani G, Cerrelli F, Lenzi M, Manini R, Natale S, Vanni E, Villanova N, Melchionda N, Rizzetto M (2003) Nonalcoholic fatty liver, steatohepatitis, and the metabolic syndrome. Hepatology 37:917-923

28. Chen CH, Huang MH, Yang JC, Nien CK, Yang CC, Yeh YH, Yueh SK (2007) Prevalence and etiology of elevated serum alanine aminotransferase level in an adult population in Taiwan. J Gastroenterol Hepatol 22:1482-1489

29. Madan K, Batra Y, Gupta SD, Chander B, Rajan KD, Tewatia MS, Panda SK, Acharya SK (2006) Non-alcoholic fatty liver disease may not be a severe disease at presentation among Asian Indians. World J Gastroenterol 12: $3400-5$

\section{Publisher's Note}

Springer Nature remains neutral with regard to jurisdictional claims in published maps and institutional affiliations. 